\title{
A New Neutral Point Voltage Control Strategy for NPC Three Level Inverters
}

\author{
Shuxi Liu*, Shan Li and Xiaoduo Yang \\ School of Electrical \&Electronic Information Engineering, Chongqing University of Technology, Chongqing, China \\ No.69, Hong-guang Road, District of Ba-nan, Chongqing \\ ${ }^{*}$ Corresponding author
}

\begin{abstract}
Multi-level inverter is now becoming an efficient and promising technology in sorts of applications, especially in high level voltage inverters. However, the unbalanced voltages between two DC-link capacitors while operating the Neutral Point Clamped (NPC) three-level inverters is an inherent problem, which in a way can excessively affect the quality of the output voltage. In this paper, a new strategy for NPC three-level inverter in DC-link balancing control is proposed. The proposed strategy is implemented by both adjusting the acting time of Ptype small vectors and $\mathrm{N}$-type small vectors in the duration times of the nearest three vectors space vector modulation and changing the switching sequences of redundant small vectors of every switching period. These two modes are selected based on the difference value of the neutral point voltage. Hence it not only has the ability to limit the large neutral point voltage drift, but also reduced the switching loss. The proposed method is simple to achieve so that complex calculation and additional hardware circuits will not be needed. The results of simulation have shown that the strategy for balancing neutral point voltage is practical and effective.
\end{abstract}

Keywords - NPC inverter; neutral point balancing; hysteresis loop; switching sequence selection

\section{INTRODUCTION}

Multi-level inverter is now becoming an efficient and promising technology in sorts of applications, such as photovoltaic and wind power grid converters, electrical high level motor systems and electric car[1][2]. Among all categories of multi-level inverters, the neutral point clamped (NPC) three-level inverter, which was firstly proposed by A. Nabae in 1980, has the most popular and substantial applications. Fig. I shows the circuit topology of the NPC three-level inverters [3].

Compared with the conventional two-level inverters, it has the advantage of generating high-voltage while the withstand voltage of power switch devices is just half of the output voltage. Furthermore, three-level inverters have lower total harmonic distortion (THD) and reduces the $\mathrm{dv} / \mathrm{dt}$ stresses on individual devices, thereby decreasing the electromagnetic interference (EMI) of the system.

As it shown in Fig. 1, the NPC three-level inverter generates different level of voltages due to the two DC-link capacitors. This issue is caused by the unbalanced charging and discharging of the two DC-link capacitors during switching cycles.
Many scholars and experts around the world have been studying this important issue in many ways for many years. Several algorithms have been proposed in the literature for balancing the neutral point voltage. Generally, the unbalanced neutral point voltage is constrained by adjusting the small vectors and medium vectors in space vector pulse width modulation (SVPWM) and injecting common mode voltage injection method (CMV) in sinusoidal pulse width modulation (SPWM) [4-8]. Nevertheless, once the neutral voltage drifts largely, the conventional modulation algorithm is hard to bring it back to the balance point.

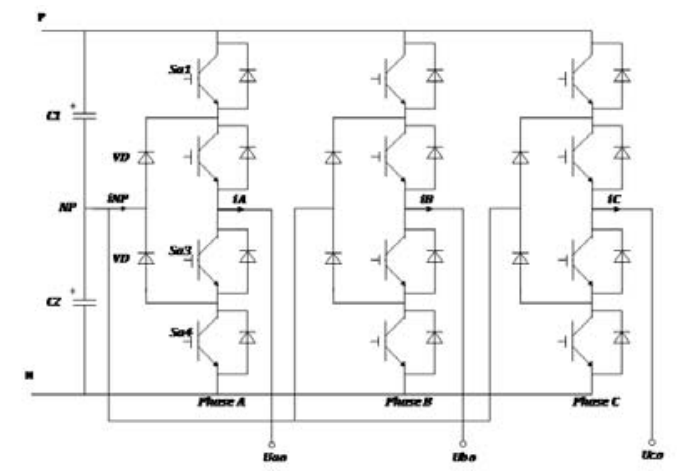

FIGURE I. NPC THREE-LEVEL INVERTER

\section{DESCRIPTION OF SVPWM FOR NPC THREE-LEVEL INVERTER}

The phase leg of NPC three-level inverter can generate three kinds of voltage states $(\mathrm{P}, \mathrm{O}$ or $\mathrm{N})$ based on the switching states of four power devices on each leg. The switching combinations for $\mathrm{P}, \mathrm{O}$ and $\mathrm{N}$ states is given in Table I. The three phase reference voltage $V_{r}$ is calculated according to (1) and switching function (2) is introduced to replace the $V_{a}, V_{b}$ and $V_{c}$. Hence, the modulation function $V_{r}^{\prime}$ for SVPWM is calculated in (3).

$$
V_{r}=V_{a}+e^{j \frac{2 \pi}{3}} V_{b}+e^{j \frac{4 \pi}{3}} V_{c}
$$




$$
\begin{aligned}
& S_{x}=\left\{\begin{array}{l}
1, P-\text { phase }-x \\
0, O-\text { phase }-x,(x=a, b, c) \\
-1, N-\text { phase }-x
\end{array}\right. \\
& V_{r}^{\prime}=\frac{V_{D C}}{2}\left(S_{a}+e^{j \frac{2 \pi}{3}} S_{b}+e^{j \frac{4 \pi}{3}} S_{c}\right)
\end{aligned}
$$

Usually, synthesizing the reference voltage is based on the SVPWM diagram for NPC three-level inverter shown in Fig. II and the nearest three vectors $(\mathrm{N} 3 \mathrm{~V})$ are used for synthesizing. According to the voltage-second balance principle, the switching time of each $\mathrm{N} 3 \mathrm{~V}$ vector is calculated in equations (4), where $V_{1}, V_{2}$ and $V_{3}$ are the three nearest vectors corresponding to reference voltage $V_{r}$, and $T_{1}, T_{2}$ and $T_{3}$ are the acting time of vectors $V_{1}, V_{2}$ and $V_{3}$ of every switching cycle $T_{s}$, respectively.

$$
\left\{\begin{array}{l}
T_{1} V_{1}+T_{2} V_{2}+T_{3} V_{3}=T_{s} V_{r} \\
T_{1}+T_{2}+T_{3}=T_{s}
\end{array}\right.
$$

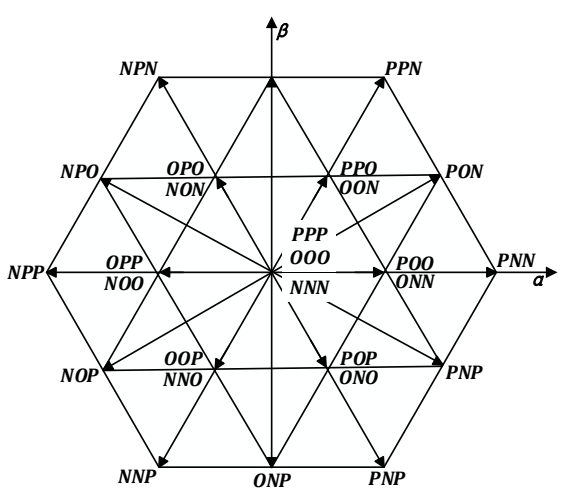

FIGURE II. SPACE VECTOR DIAGRAM FOR NPC THREE LEVEL INVERTER

TABLE I. SWITCHING COMBINATIONS

\begin{tabular}{|c|c|c|c|c|c|}
\hline \multirow{2}{*}{ States } & \multirow{2}{*}{$\begin{array}{c}\text { Output } \\
\text { Voltage }\end{array}$} & \multicolumn{4}{|c|}{$\begin{array}{c}\text { Power Device Switching } \\
\text { States(x=a, b or c) }\end{array}$} \\
\cline { 3 - 6 } & Sx1 & Sx2 & Sx3 & Sx4 \\
\hline $\mathrm{P}$ & $V_{D C} / 2$ & ON & ON & OFF & OFF \\
\hline $\mathrm{O}$ & 0 & OFF & ON & ON & OFF \\
\hline $\mathrm{N}$ & $-V_{D C} / 2$ & OFF & OFF & ON & ON \\
\hline
\end{tabular}

While operating SVPWM in NPC three-level inverter, different reference voltage and different combinations of switching states have effects on the two DC-link capacitors, which in a way influence the neutral point voltage. The vectors in Fig. II are categorized into four types shown in Table II which are zero vectors, small vectors, medium vectors and large vectors according to its magnitude. Among these vectors, only small vectors and medium vectors can influence the neutral point voltage [9].

TABLE II. TYPES OF THE VECTORS

\begin{tabular}{|c|c|l|}
\hline Type & \multicolumn{1}{|c|}{ Vector } & Magnitude \\
\hline Zero Vectors & PPP,OOO,NNN & 0 \\
\hline Small Vectors & $\begin{array}{c}\text { POO,PPO,OPO, } \\
\text { OPP,OOP,POP, } \\
\text { ONN,OON,NON, } \\
\text { NOO,NNO,ONO }\end{array}$ & $V_{D C} / 3$ \\
\hline Medium Vectors & $\begin{array}{l}\text { PON,OPN,NPO, } \\
\text { NOP,ONP,PNO }\end{array}$ & $\sqrt{3} V_{D C} / 3$ \\
\hline Large Vectors & $\begin{array}{l}\text { PNN,PPN,NPN, } \\
\text { NPP,NNP,PNP }\end{array}$ & $2 V_{D C} / 3$ \\
\hline
\end{tabular}

The medium vectors cannot be controlled due to the fact that the NP voltage is determined by the direction of the connected phase. In small vectors, P-type small vectors discharge the upper capacitor $\mathrm{C} 1$ while the N-type small vectors discharge the lower capacitor $\mathrm{C} 2$, and hence the NP voltage can be controlled by the small vectors.

In summary, the unbalancing of the NP voltage can be controlled by indirectly applying the acting time of small vectors and suited switching sequence.

\section{Proposed NP Voltage Balancing CONTROL STRATEGY}

The conventional SVPWM NP point voltage balancing control strategy is applied by adjusting the acting time of both P-type small vectors and N-type small vectors in every switching cycle. The acting time is controlled by detecting the difference between the two DC-link capacitors and the current in neutral point. This hysteresis loop strategy is easily controlled and effective. However, the control effect is determined by the power factor and causes huge switching loss at the duration time.

The proposed strategy in this paper is based on the conventional hysteresis loop SVPWM NP point voltage balancing control strategy. As it shown in Fig.3, Add switching sequence selection strategy into hysteresis loop control strategy to get better control effect. 


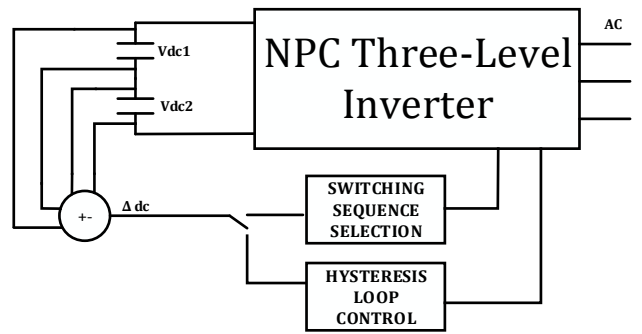

FIGURE III. SCHEMATIC DIAGRAM OF THE PROPOSED CONTROL STRATEGY

Changing the two control strategy by detecting the difference value of the two DC-link capacitors at the real time. As it shown in Fig.4, a is the changing point of the two strategy.

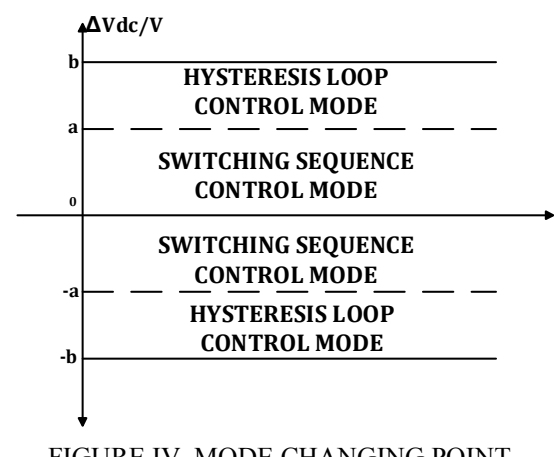

$$
\text { FIGURE IV. MODE CHANGING POINT }
$$

While $\Delta V_{D C} \in[-a, a]$, the switching sequence mode is selected to control the NP voltage, thereby limiting the fluctuation as long as reducing the switching loss. Furthermore, if $\Delta V_{D C} \in[a, b]$ or $\Delta V_{D C} \in[-b,-a]$, the hysteresis loop NP control mode is applied to bring the NP voltage back to balanced state.

\section{RESUltS AND CONCLUSION}

The simulation of the proposed neutral point voltage strategy and SVPWM algorithm has been carried at switching frequency $10 \mathrm{kHz}$. The voltage supply is $200 \mathrm{~V}$ and divided by two DC-link capacitor. Three phase R-L load is implemented in the simulation with $10 \Omega$ resistance and $5 \mathrm{e}-2 \mathrm{~L}$ inductance.

Fig. 5 shows that when an unbalancing state occurs between two DC-link capacitors, while $\Delta V_{D C}>2 \mathrm{~V}$, the hysteresis loop $\mathrm{NP}$ voltage control mode is selected to bring the drift voltage back to 0 , after $\Delta V_{D C} \in[-2,2] \mathrm{V}$, the switching sequence mode is applied to keep the NP voltage into small scale of fluctuation. Fig.6 and Fig.7 show the line voltage and neutral point current, respectively.

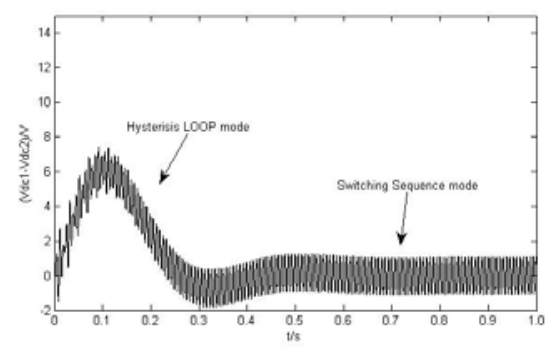

FIGURE V. EFFECT OF PROPOSED STRATEGY ON NP VOLTAGE

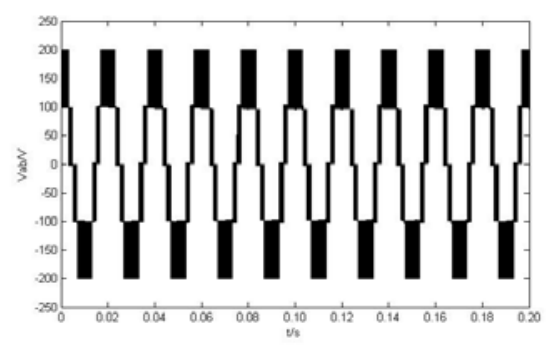

FIGURE VI. LINE VOLTAGE OF OUTPUT

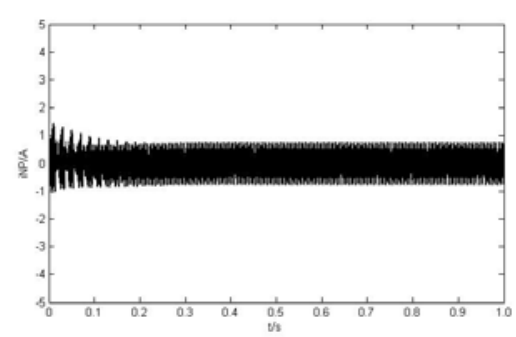

FIGURE VII. CURRENT OF NEUTRAL POINT

Results show that the proposed switching sequence selection along with hysteresis loop neutral point voltage control strategy has high controllability and strong balancing ability even if with large imbalance. Furthermore, the switching loss is reduced compared with conventional strategy.

\section{REFERENCES}

[1] J. Rodriguez, S. Bernet, P. K. Steimer, and I. E. Lizama, "A survey on neutral-point-clamped inverters," IEEE Transactions on Industrial Electronics, vol. 57, no. 7, pp. 2219-2230, Jul. 2010. J. Clerk Maxwell, A Treatise on Electricity and Magnetism, 3rd ed., vol. 2. Oxford: Clarendon, 1892, pp.68-73.

[2] A. Nabae, T. Takahashi, and H. Akagi, "A new neutral-point-clamped PWM inverter," in Conf. Rec. IEEE IAS Annu. Meeting, Cincinnati, OH,Sep. 28-Oct. 3 1980, pp. 761-776.

[3] U. M. Choi, J. S. Lee, and K. B. Lee, "New modulation strategy to balance the neutral-point voltage for three-level neutral-clamped inverter systems," IEEE Trans. Energy Convers., vol. 29, no. 1, pp. 91-100, Mar. 2014.

[4] C. Newton and M. Summer, "Neutral point control for multi-level inverters: Theory, design and operational limitations," in Conf. Rec. IEEE IAS Annu. Meeting, 1997, pp. 1336-1343.

[5] X. Lin, S. Gao, J. Li, H. Lei, and Y. Kang, "A new control strategy to balance neutral-point voltage in three-level NPC inverter," in Proc. IEEE ICPE, 2011, pp. 2593-2597.

[6] A. Lewicki, Z. Krzeminski, and H. Abu-Rub, "Space-vector pulsewidth modulation for three-level NPC converter with the neutral point voltage 
control,” IEEE Trans. Ind. Electron., vol. 58, no. 11, pp. 5076-5086,Nov. 2011.

[7] Y.-H. Ko, B.-G. Park, R.-Y. Kim, D.-S. Hyun, and H.-J. Jung, “A simple space vector PWM scheme with neutral point balancing for three-level neutral point clamped inverter," in Proc. IEEE Ind. Appl. Soc., 2011,pp. $1-6$

[8] J. Pou, J. Zaragoza, S. Ceballos, M. Saeedifard, and D. Boroyevich, “A carrier-based PWM strategy with zero-sequence voltage injection for a three-level neutral-point-clamped converter," IEEE Trans. Power Electron., vol. 27, no. 2, pp. 642-651, Feb. 2012.

[9] M.S. Newton C, "Neutral point control for multilevel inverters: theory, design and operational limitations", IEEE transaction on Industrial application, vol no 2, 1997, pp. 1336-1343. 